\title{
A!
}

This is an electronic reprint of the original article.

This reprint may differ from the original in pagination and typographic detail.

Peitso, P.; Tanskanen, E. I.; Pulkkinen, T. I.; Mursula, K.

\section{High-Frequency Geomagnetic Fluctuations at Auroral Oval and Polar Cap}

\section{Published in:}

Space Weather

DOI:

10.1029/2018SW001841

Published: 01/08/2018

Document Version

Publisher's PDF, also known as Version of record

Please cite the original version:

Peitso, P., Tanskanen, E. I., Pulkkinen, T. I., \& Mursula, K. (2018). High-Frequency Geomagnetic Fluctuations at Auroral Oval and Polar Cap. Space Weather, 16(8), 1057-1072. https://doi.org/10.1029/2018SW001841

This material is protected by copyright and other intellectual property rights, and duplication or sale of all or part of any of the repository collections is not permitted, except that material may be duplicated by you for your research use or educational purposes in electronic or print form. You must obtain permission for any other use. Electronic or print copies may not be offered, whether for sale or otherwise to anyone who is not an authorised user. 


\section{Space Weather}

\section{RESEARCH ARTICLE \\ 10.1029/2018SW001841 \\ High-Frequency Geomagnetic Fluctuations at Auroral Oval and Polar Cap}

Key Points:

- The largest differences in seasonal variation between noon and midnight are seen in the polar cap

- Midnight hosts most fluctuations below 72 and noon above 72 degrees geomagnetic latitude

- Latitudinal differences are larger in

fluctuation coverage (FDR) than in amplitude $(\mathrm{d} H / \mathrm{d} t)$

Correspondence to:

P. Peitso,

pyry.peitso@aalto.fi

Citation:

Peitso, P., Tanskanen, E. I.,

Pulkkinen, T. I., \& Mursula, K. (2018).

High-frequency geomagnetic

fluctuations at auroral oval and

polar cap. Space Weather, 16.

https://doi.org/10.1029/2018SW001841

Received 22 FEB 2018

Accepted 5 JUL 2018

Accepted article online 23 JUL 2018

\author{
P. Peitso ${ }^{1,2,3}$ iD , E. I. Tanskanen ${ }^{1}$ (D) T. I. Pulkkinen4 ${ }^{(D)}$, and K. Mursula ${ }^{3}$ id \\ ${ }^{1}$ ReSoLVE Centre of Excellence, Aalto University, Espoo, Finland, ${ }^{2}$ Finnish Meteorological Institute, Helsinki, Finland, \\ ${ }^{3}$ University of Oulu, ReSoLVE Centre of Excellence, Oulu, Finland, ${ }^{4}$ School of Electrical Engineering, Aalto University, \\ Espoo, Finland
}

Abstract Rapid magnetic fluctuations are known to be closely linked to the high-latitude geomagnetic activity, in particular, to geomagnetic pulsations and subtorms. Increasing amount of commercial activity in the arctic regions requires better monitoring capability and improved understanding on the effects of geomagnetic hazards to infrastructure. In this study, we analyze rapid, 1-s fluctuations in Greenland. To measure high-frequency geomagnetic fluctuations in the auroral oval and polar cap, we use high time resolution data of $1 \mathrm{~s}$ from 12 stations covering a large latitudinal range of 64 to 84 quasi-dipole geomagnetic latitude (QDGMlat). We found out that the large magnetic field fluctuations exceeding $0.2 \mathrm{nT} / \mathrm{s}$ are observed $10-30 \%$ of the time in auroral oval latitudes, depending on the solar cycle phase and station location. The latitudinal differences are much larger in fluctuation coverage (fractional derivative rate, FDR) than in fluctuations amplitude $(\mathrm{d} H / \mathrm{d} t)$. The highest $|\mathrm{d} H / \mathrm{d} t|$ and FDRs at noon are observed at the northern stations from 72 to 84 QDGMlat, while in south Greenland from 72 to 65 QDGMlat, the highest $|\mathrm{d} H / \mathrm{d} t|$ and FDRs are recorded at midnight. The largest differences in seasonal variation between noon and midnight are observed in the polar cap, where a summer increase is seen at noon and almost flat seasonal profile at midnight.

Plain Language Summary We analyze Earth's magnetic field measurements from Greenland in 2011-2013. We use high time resolution measurements obtained from 12 stations, covering a large geographic area. We use the rate of change of the magnetic field as the basis of our analysis, and we have developed a new method called the fractional derivative rate for this purpose. Differences between the years, time of day, and geographic location along the north-south axis are studied separately. We found out that there are significant differences between the stations, with the northernmost stations being more magnetically active during noon and the southernmost stations more active during midnight. The largest differences in these activity patterns are seen in the northernmost area, the polar cap. Understanding these variations in activity between the geographic locations will help us prepare more accurate and better targeted space weather forecasts in the future.

\section{Introduction}

Understanding the behavior of the magnetic field fluctuations in several different timescales is important for space weather research and forecasting. Both seasonal patterns as well as pulsations in the timescale of seconds need to be understood. The information on rapid geomagnetic fluctuations from the 1-s data is useful for aviation, telecommunication, navigation, and services related to the electric power and energy supply. Commercial activity has significantly increased in the arctic region during the past few years. A wide variety of infrastructure are affected by space weather, including shipping, airlines, and oil and gas exploration and mining. Space weather research and forecasting require more accuracy than in the previous decades in this new area of operation, and understanding of the fluctuations is important. Geographically more precise space weather forecasting will require more detailed studies of the magnetic field variations by latitude.

Space weather refers to the solar originated disturbances that affect space from the Sun to the edges of the heliosphere, including the Earth. Space weather includes the extreme conditions during which the disturbances have great potential to damage various infrastructures and, in the worst case, endanger humans in space. Space weather manifests itself in numerous ways, such as the northern lights and disturbances in the 
geomagnetic field (Kivelson \& Russell, 1995; Koskinen, 2011; Koskinen et al., 2001). A substorm is a transient process that deposits energy and particles from the solar wind and magnetosphere into the auroral ionosphere (Akasofu, 1964), while storms are large-scale disturbances lasting up to several days and often include strong substorm activity (Gonzalez et al., 1994). The amount of energy transferred from the solar wind into the magnetosphere by substorms in yearly timescales is larger than that during geomagnetic storms (Tanskanen et al., 2002). The geomagnetic activity is known to occur in a semiannual pattern (Russell \& McPherron, 1973). Substorms and other more rapid magnetic field fluctuations such as geomagnetic pulsations and their manifestations, such as geomagnetically induced currents (GIC), are continuously monitored by several instruments, including high-latitude magnetometers, all-sky cameras, radars, and satellites.

Geomagnetic measurements have been conducted at observatories around the world since the midnineteenth century. Several international magnetometer networks were established during the twentieth century, improving the coverage of magnetic measurements. Currently, significant high-latitude magnetometer networks include the Canadian Array for Realtime Investigations of Magnetic Activity (Mann et al., 2008), International Monitor for Auroral Geomagnetic Effects (IMAGE) in Fenno-Scandinavia and Baltic countries (Tanskanen, 2009), and Greenland east and west coast magnetometer chains (Friis-Christensen et al., 1985). Magnetic measurements in Greenland started as early as 1926 and have continued almost continuously since then.

Rapid magnetic field fluctuations are closely linked to several space weather phenomena, most notably fluctuations in Pc and Pi frequency ranges and substorms. Understanding the latitudinal changes of fluctuation amplitude and coverage of 1-s fluctuations allow defining where and when solar storm-related disturbances hit the worst for critical infrastructure.

The spatial coverage, data quality, and resolution of high-latitude geomagnetic measurements have improved in recent decades. So far, the temporal resolution of $1 \mathrm{~min}$, or at most $10 \mathrm{~s}$, has been the international standard for decades (e.g., in International Real-time Magnetic Observatory Network). The instrumentation in Greenland has recently been upgraded, and the 1-s resolution measurements are available from a few stations since 2010 and from several stations since 2011, while the earlier, lower frequency measurements and the geomagnetic activity indices derived from them have been widely utilized (Lukianova et al., 2012; Mursula et al., 2015; Tavares et al., 1997). This high-frequency data (1-s) have been so far left unanalyzed to full detail.

Viljanen and Tanskanen (2011) analyzed IMAGE magnetic measurements in 1983-2010 using 10- and 60-s resolution data and found that the time derivative $|\mathrm{d} H / \mathrm{d} t|$ is large around midnight and in the early morning hours, at 05-09 magnetic local time (MLT). They concluded that large $|\mathrm{d} H / \mathrm{d} t|$ values occur predominantly in the westward electrojet region. Juusola et al. (2015) studied the time derivatives of ionospheric equivalent current vectors in 1994-2013 using the 10-s data of IMAGE magnetometers. They found that the time derivatives of ionospheric equivalent current vectors have two MLT peaks: one in the premidnight sector and the other in the prenoon sector. They also noted that the prenoon (08-10 MLT) enhancement of the equivalent currents correlates with fast solar wind, while the premidnight (22-00 MLT) peak correlates with the southward orientation of the interplanetary magnetic field (IMF).

Guo et al. (2012) studied auroral electrojets using IMAGE magnetometers. They found that in the MLT sectors 1230-2230 for IU and 2230-0630 for ILindices, these indices are better proxies for global activity than $A U$ and $A L$ indices respectively. T. I. Pulkkinen et al. (2011) studied the latitudinal location of the annually averaged electrojets. The average geomagnetic latitude of electrojet was found to be close to $72^{\circ} \mathrm{GMlat}$ at midnight hours. During dusk hours, the eastward electrojet latitude was, on average, slightly more southward than the westward electrojet at midnight, but there was more variance in the measured location at dusk than at midnight. During dawn hours, the mean latitude of electrojet was $73^{\circ} \mathrm{GMlat}$. They also noted that the electrojets were located roughly $2^{\circ}$ more poleward in the deep minimum years of solar cycle 23 in 2006-2010 than in the previous minimum of cycle 22 in 1995-1999.

Holappa, Mursula, Asikainen, and Richardson (2014) studied the latitudinal variation of geomagnetic activity by using the annually averaged geomagnetic data from 26 stations covering a wide latitude range from $9.52^{\circ}$ to $86.00^{\circ} \mathrm{CGMlat}$ and the years $1966-2009$. They applied principal component analysis to the activity indices of these stations and found that the first principal component correlates well with global geomagnetic activity and that the second component is highly correlated with the fraction of time high-speed streams (HSS) occurring in solar wind. The latitudinal distribution of the second component has a maximum at auroral latitudes 
Table 1

Greenland Magnetometers and Their Coordinates, Abbreviations, Possible Former Names, and Location in Quasi-Dipole Geomagnetic and Geographic Coordinates

\begin{tabular}{|c|c|c|c|c|c|c|}
\hline Station & Full name & Former name & QDGMlat & QDGMlon & GGlat & GGlon \\
\hline $\mathrm{THL}^{\mathrm{a}}$ & Qaanaaq & Thule & 83.97 & 26.61 & 77.47 & 69.23 \\
\hline SVSa & Savissivik & - & 82.24 & 30.58 & 76.02 & 65.10 \\
\hline KUVa $^{\mathrm{a}}$ & Kullorsuaq & - & 79.91 & 39.67 & 74.57 & 57.18 \\
\hline UPN $^{\mathrm{b}}$ & Upernavik & - & 78.11 & 38.37 & 72.78 & 56.15 \\
\hline $\mathrm{DMH}^{\mathrm{b}}$ & Danmarkshavn & - & 76.90 & 81.60 & 76.77 & 18.63 \\
\hline $\mathrm{UMQ}^{\mathrm{b}}$ & Uummannaq & Umanaq & 75.52 & 40.99 & 70.68 & 52.13 \\
\hline $\mathrm{GDH}^{\mathrm{b}}$ & Qeqertarsuaq & Godhavn & 74.35 & 38.04 & 69.25 & 53.53 \\
\hline STFC & Kangerlussuaq & Sondre Stromfjord & 71.70 & 39.70 & 67.02 & 50.72 \\
\hline SKT ${ }^{\mathrm{C}}$ & Maniitsoq & Sukkertoppen & 70.46 & 36.27 & 65.42 & 52.90 \\
\hline $\mathrm{GHB}^{\mathrm{C}}$ & Nuuk & Godthaab & 68.99 & 36.98 & 64.17 & 51.71 \\
\hline $\mathrm{FHB}^{\mathrm{C}}$ & Paamiut & Frederickshaab & 66.38 & 38.28 & 62.00 & 49.68 \\
\hline $\mathrm{NAQ}^{\mathrm{C}}$ & Narsarsuaq & - & 64.70 & 42.36 & 61.16 & 45.44 \\
\hline
\end{tabular}

The three groups of stations:

a polar cap, b north oval, and c south oval. Station abbreviations are often based on the former name of station.

(65-75 CGMlat). Holappa, Mursula, and Asikainen (2014) found that solar wind speed is the most important parameter driving geomagnetic activity during HSS, while the IMF strength dominates during interplanetary coronal mass ejections (CME).

Finch et al. (2008) used 270 stations ranging over all latitudes to study the latitudinal change in solar wind-magnetosphere coupling. They used the $\sigma_{n}^{H}$ index, which is the value of the standard deviation of the hourly averaged horizontal component of the magnetic field. They included all available hourly mean magnetometer data from the World Data Center for Geomagnetism in Edinburgh, resulting in more than a century of measurements. They found that geomagnetic activity in latitudes below $70^{\circ}$ correlates better with IMF magnitude, but there is a strong correlation with solar wind speed at higher latitudes above $70^{\circ}$.

The latitudinal variation of geomagnetic disturbances was studied by Myllys et al. (2015) by using the standard deviation of the magnetic field north-south component. They found that the standard deviation of geomagnetic activity at high latitudes $\left(63-75^{\circ} \mathrm{GMlat}\right)$ correlates best with high-speed solar wind and substorm activity, while at lower latitudes activity is mainly driven by CMEs.

We study the monthly means of $|\mathrm{d} H / \mathrm{d} t|$ constructed directly from 1-s data. In this way, we can observe phenomena related to the rapid variations of the horizontal magnetic field. We introduce a new parameter called the fractional derivative rate (FDR), with the purpose of studying the occurrence of the high-frequency geomagnetic disturbances. We will use high-frequency magnetic field measurements from 12 selected Greenland stations from 2011 to 2013. The large latitudinal coverage and the high time resolution of data allow us to observe high-frequency geomagnetic fluctuations and their latitudinal distribution, as well as seasonal and MLT variation parametrized by $|\mathrm{d} H / \mathrm{d} t|$ and the FDR. The paper is organized as follows: in section 2, we present the data from the different Greenland magnetometer stations. In section 3 we study the monthly fluctuation levels using $|\mathrm{d} H / \mathrm{d} t|$. In section 4 we compare the fluctuation rates at noon and midnight, while in section 5 we look at the probability density functions (PDFs) of fluctuations. In section 6 , we present the FDR. In section 7 , we discuss and compare the results, while in section 8 we present the conclusions.

\section{Data and Methods}

The data set used here was recorded at the magnetometer stations located at Greenland and operated by Danish Technical University. The selected stations and their geographic and quasi-dipole geomagnetic coordinates (Emmert et al., 2010) are listed in Table 1. The Greenland stations cover a large latitudinal range from $65^{\circ}$ to $84^{\circ}$ QDGMlat, making them ideal for studies of polar cap, auroral oval, and other high-latitude phenomena. Figure 1 depicts the locations of the 12 Greenland magnetometers that are used in this paper along with their geomagnetic latitudes. The location of the geomagnetic north (dipole) pole in 2012 (realization obtained from http://wdc.kugi.kyoto-u.ac.jp/poles/polesexp.html) is shown in Figure 1 by the red square. 


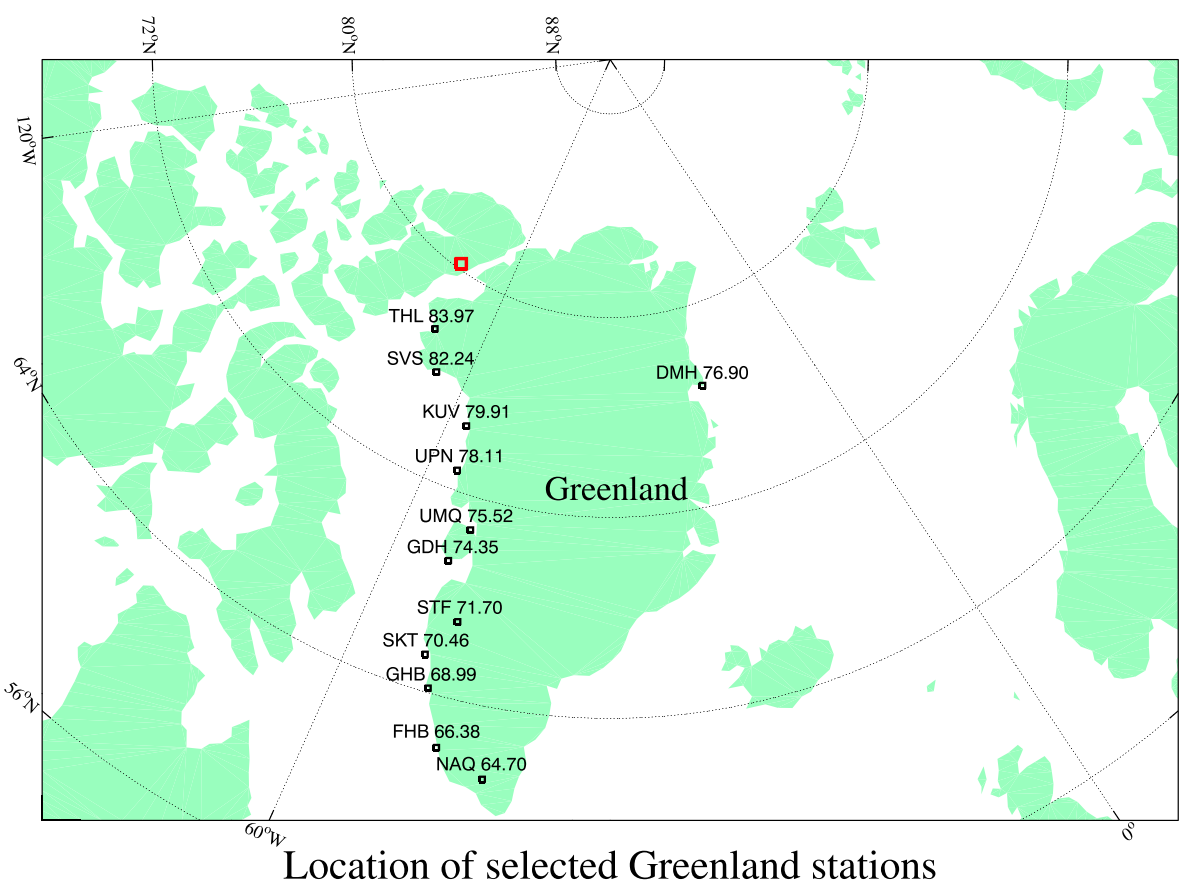

Figure 1. The location of Greenland magnetometer stations, station codes and quasi-dipole geomagnetic latitudes in geographic coordinate system. The geomagnetic north dipole pole in 2012 is noted as a red square.

We use the $H$ components of the magnetic field at 1-s resolution (along the local magnetic north direction, positive northward). Furthermore, we mainly use the $|\mathrm{d} H / \mathrm{d} t|$ to emphasize the short-term magnetic field fluctuations and their space weather effects over the time span of several years.Derivative values are better for intercomparison purposes, due to the challenges in defining the absolute magnetic field baselines for the 12 chosen stations.

We divide the Greenland magnetometer network into three latitudinal sectors: polar cap (north Greenland), north oval (mid-Greenland), and south oval (south Greenland) stations. The corresponding ranges in quasi-dipole geomagnetic coordinates are $79.91^{\circ}$ to $83.97^{\circ}, 74.35^{\circ}$ to $78.11^{\circ}$, and $64.70^{\circ}$ to $71.70^{\circ}$ QDGMlat, respectively. Stations included in the polar cap sector are Qaanaaq, Savissivik, and Kullorsuaq (THL, SVS, and KUV); in the north oval sector are Upernavik, Danmarkshavn, Uummannaq, and Qeqertarsuaq (UPN, DMH, UMQ, and GDH); and in the south oval sector are Kangerlussuaq, Maniitsoq, Nuuk, Paamiut, and Narsarsuaq (STF, SKT, GHB, FHB, and NAQ). The stations also have former names that are sometimes used in the literature. From here on out we only use the station abbreviations listed above. Note that the south oval sector included not only auroral but also subauroral stations. High-frequency fluctuations are studied separately in two different magnetic local time sectors defined here as follows: the noon (10-14) MLT sector and midnight (22-02) MLT sector. These time sectors were chosen because they well illustrate the latitudinal differences of high-frequency fluctuation amplitude and fluctuation coverage, and they are wide enough ( $4 \mathrm{hr}$ each) to cover the prenoon and premidnight in addition to $2 \mathrm{hr}$ of postnoon and postmidnight.

\section{Monthly Fluctuation Levels of $|\mathrm{d} H / \mathrm{d} t|$}

The monthly averaged values of $|\mathrm{dH} / \mathrm{d} t|$ constructed from the 1-s data are used to study the latitudinal differences in high-frequency geomagnetic fluctuations. The stations are depicted in three panels consisting of the polar cap, north oval, and south oval latitudinal sectors.

Figure 2 shows the monthly averaged $|\mathrm{d} H / \mathrm{d} t|$ using data from all MLT sectors, that is, full day, in 2011-2013. The northernmost Greenland station Thule (THL) at $83^{\circ}$ QDGMlat has an average $|\mathrm{d} H / \mathrm{d} t|$ fluctuation level of roughly $0.12 \mathrm{nT} / \mathrm{s}$ (Figure 2a). THL monthly means exhibit very little variation over the 3-year interval, with the exception of a slight increase during summer months compared with winter. Note that the THL data resolution appears slightly lower than $0.1 \mathrm{nT}$, roughly $0.3-0.4 \mathrm{nT}$, due to instrument issues (Jürgen Matzka, personal communication, October 12, 2017). Despite slightly different performance than the other stations, we have 

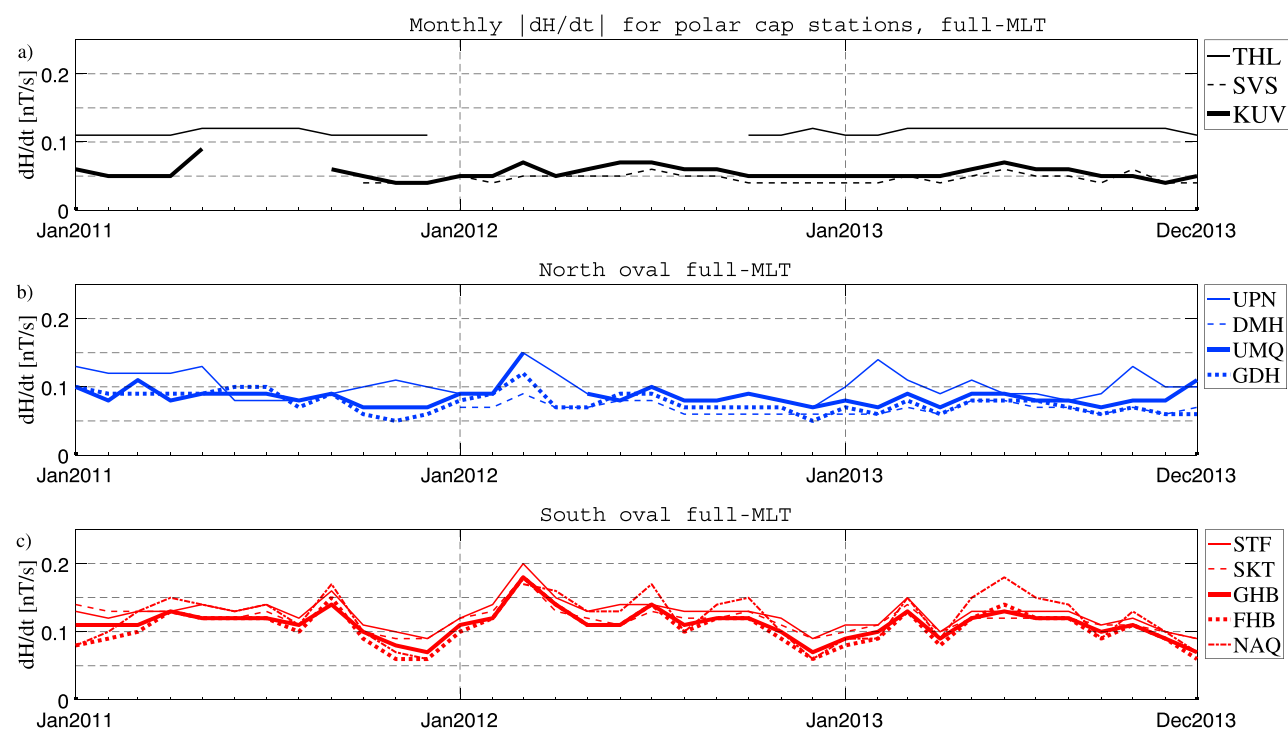

Figure 2. Monthly averages of $|\mathrm{d} H / \mathrm{d} t|$ calculated from 1-s data in 2011-2013. Stations are grouped according to quasi-dipole geomagnetic latitude from (a) polar cap, (b) north oval, and (c) south oval. MLT = magnetic local time.

decided to include THL as part of our study due to its unique location deep in the polar cap. The second northernmost station SVS at $82^{\circ}$ QDGMlat has an overall average $|\mathrm{d} H / \mathrm{d} t|$ of $0.05 \mathrm{nT} / \mathrm{s}$, that is, only half of the average level of THL. The temporal variation of $|\mathrm{d} H / \mathrm{d} t|$ at SVS is almost as flat as in THL, but the summer maximum is somewhat more prominent than in THL. The third station $\mathrm{KUV}$ at $79^{\circ}$ QDGMlat has a slightly higher average fluctuation level than SVS and depicts the summer maximum even slightly more clearly than SVS. In addition, KUV depicts some other temporal variability, for example, the small maximum in early 2012.

Three north oval stations $\mathrm{DMH}, \mathrm{UMQ}$, and GDH, (Figure $2 \mathrm{~b}$ ), have a rather similar variation of $|\mathrm{d} H / \mathrm{d} t|$, which is clearly different than $|\mathrm{d} H / \mathrm{d} t|$ variations in UPN. The summer enhancement is seen also at these three north oval stations, but there is slightly more temporal variability than at the polar cap sector stations. These three north oval stations have roughly similar average fluctuation levels of about $0.08 \mathrm{nT} / \mathrm{s}$ and interannual trends that are different compared with UPN. The average fluctuation level of UPN at $78^{\circ}$ QDGMlat is clearly higher than for the other three north oval stations, about $0.10 \mathrm{nT} / \mathrm{s}$. In addition, it tends to have additional maxima at times (e.g., in November 2011 and February 2013) when none of the other stations show any activity maxima.

All five of the south oval stations, STF, SKT, GHB, FHB, and NAQ (Figure 2c), depict closely similar variations and have very similar average fluctuation levels of about $0.11 \mathrm{nT} / \mathrm{s}$. STF exhibits a slightly higher monthly average level $(0.13 \mathrm{nT} / \mathrm{s}$ ) than the other south oval stations (SKT $0.12 \mathrm{nT} / \mathrm{s}$, GHB $0.11 \mathrm{nT} / \mathrm{s}$, FHB $0.11 \mathrm{nT} / \mathrm{s}$, and NAQ $0.12 \mathrm{nT} / \mathrm{s}$ ). The seasonal variation is also very similar in all south oval stations, but they display more variability than the stations of the polar cap and north oval sectors. Moreover, the summer maximum is not present for the south oval stations, at least during 2011 and 2012.

\section{Monthly Fluctuation Levels of $|\mathrm{d} H / \mathrm{dt}|$ at Noon and Midnight}

The monthly averaged values of $|\mathrm{dH} / \mathrm{d} t|$ at noon (10-14 MLT) and midnight (22-02 MLT) are shown for the polar cap, north oval, and south oval stations in Figures 3 and 4, respectively. At noon, the polar cap stations show increased $|\mathrm{d} H / \mathrm{d} t|$ compared with the full MLT, particularly during the summer season (Figure 3). The average fluctuation level of SVS and KUV at noon, about $0.10 \mathrm{nT} / \mathrm{s}$, is roughly twice that of the full-MLT level ( 0.05 and $0.06 \mathrm{nT} / \mathrm{s}$, respectively). Differences between noon and full MLT are less prominent in THL where the fluctuation level is only slightly higher and the summer maximum somewhat more pronounced at noon than in the full-MLT case. The summer fluctuation maximum and the 2012 spring peak is clearly visible at all other stations, except THL.

The temporal variation of $|\mathrm{d} H / \mathrm{d} t|$ at north oval stations is fairly uniform, even in the noon sector, although their average levels have a larger mutual spread than for full MLT. The average $|\mathrm{d} H / \mathrm{d} t|$ at noon is also higher 

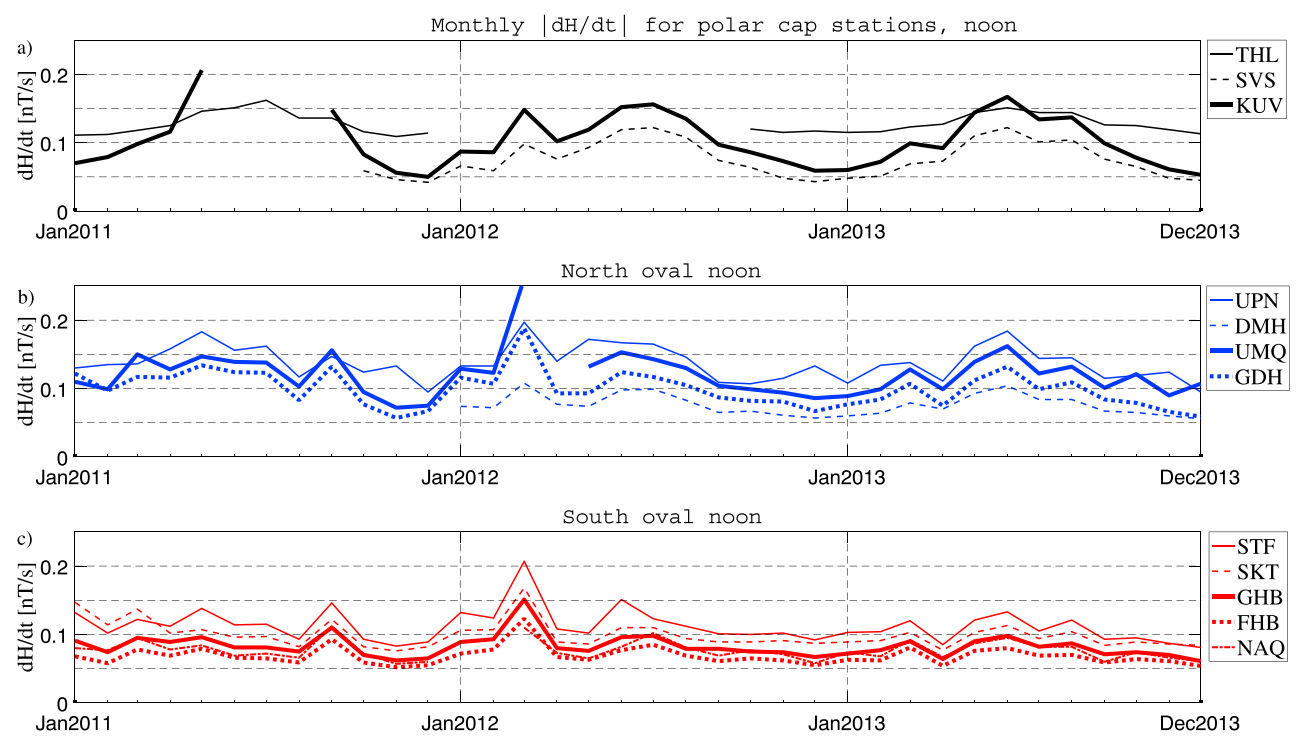

Figure 3. Same as Figure 2, but only data from the noon sector (10-14 MLT) are included. MLT = magnetic local time.

than for the full MLT. From these stations, UPN has the highest level of monthly fluctuations, roughly $0.14 \mathrm{nT} / \mathrm{s}$. For the other north oval stations, the average $|\mathrm{d} H / \mathrm{d} t|$ at noon varies between 0.08 and $0.12 \mathrm{nT} / \mathrm{s}$. Note that the lowest level of $|\mathrm{d} H / \mathrm{d} t|$ is found at $\mathrm{DMH}$, which is the only station located at the east coast of Greenland.

Interestingly, at the south oval stations, the $|\mathrm{d} H / \mathrm{d} t|$ and the annual variation at noon MLT are smaller than those at midnight MLT. Of the south oval stations, STF has the largest fluctuation levels. The $|\mathrm{d} H / \mathrm{d} t|$ for STF is about $0.11 \mathrm{nT} / \mathrm{s}$, that is, roughly the same as for full MLT. The other south oval stations have fluctuations of approximately $0.07-0.10 \mathrm{nT} / \mathrm{s}$ at noon. Highest $|\mathrm{d} H / \mathrm{d} t|$ fluctuations occur during autumn 2011 and spring 2012. There is a weak maximum at noon during summer 2013, which is weaker than for full MLT, or for the polar cap or north oval stations.

Overall, when comparing the noon sector with the full-MLT results, we can see that the fluctuation rates are greatly increased at the polar cap in summer. This summer increase around noon is also visible at north oval stations, where fluctuation activity is likewise increased at other times, especially in the fall of 2011 and spring 2012. High-frequency fluctuations are more rare at noon than other MLTs for the south oval.
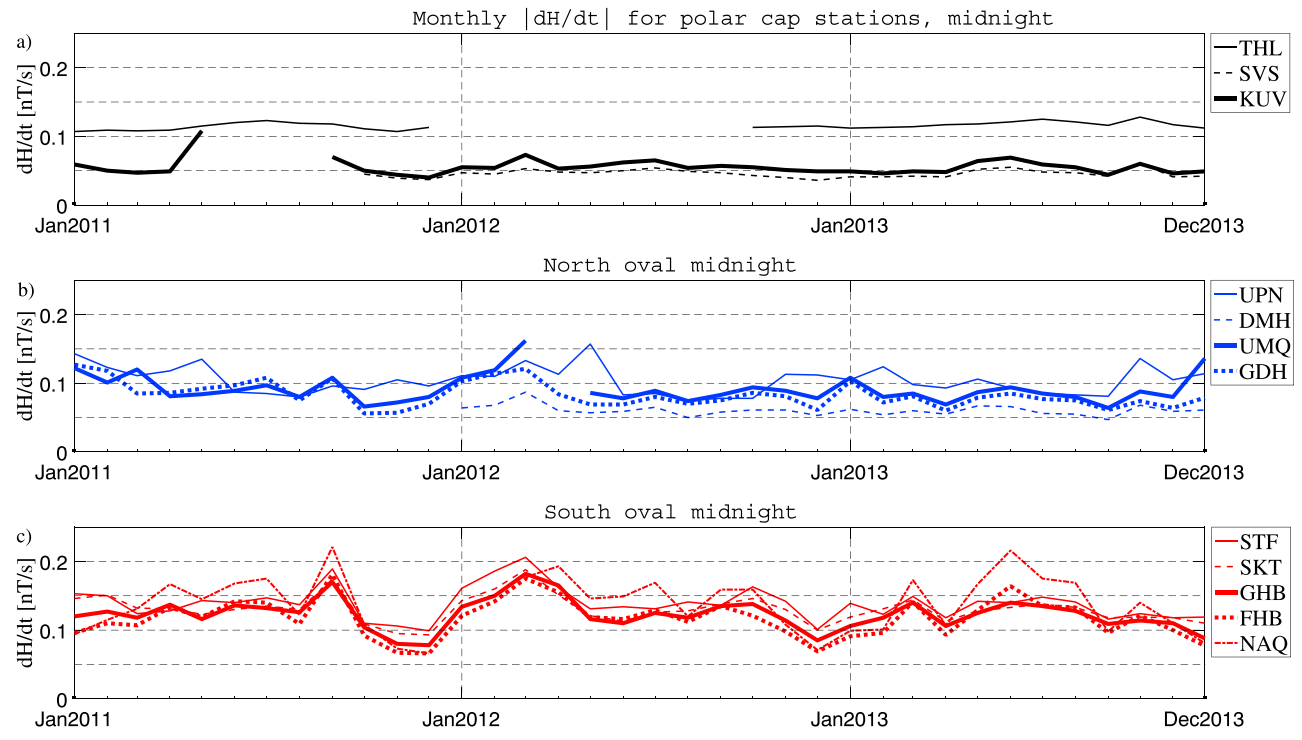

Figure 4. Same as figure 2, but only data from the midnight sector (22-02 MLT) are included. MLT = magnetic local time. 


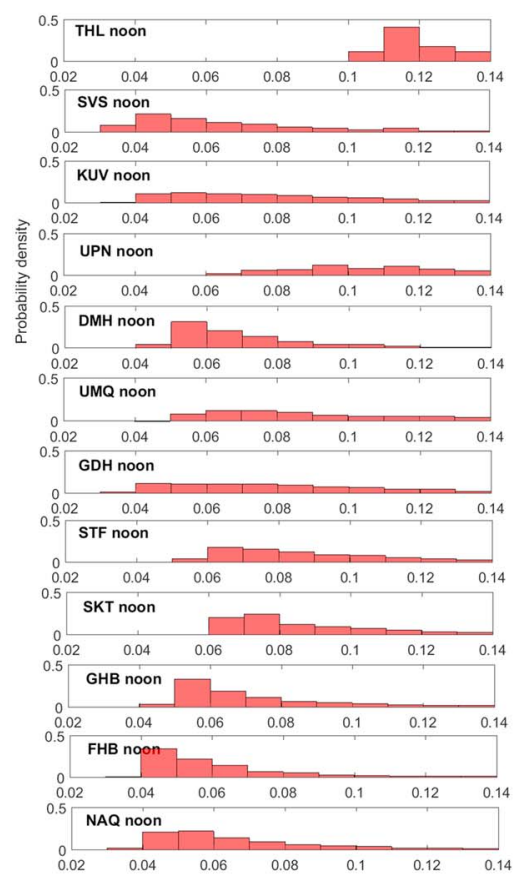

Daily |dH/dt| PDF distribution in 2011-2013
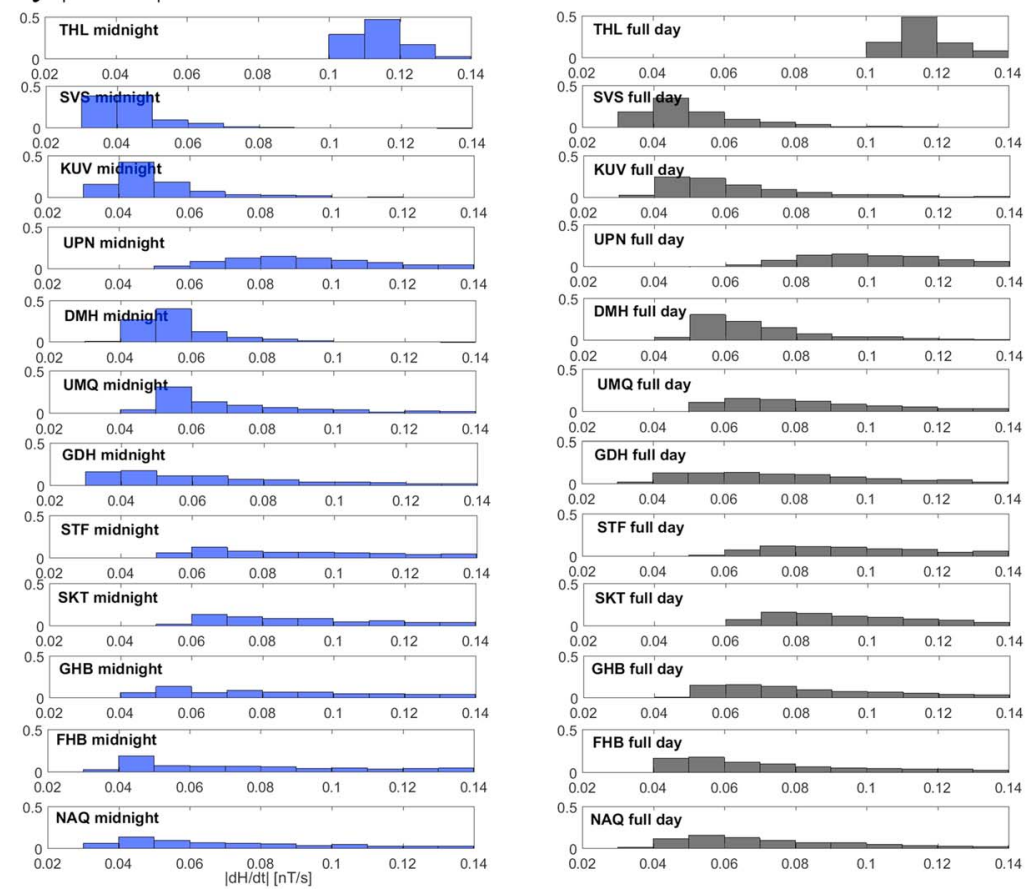

Figure 5. Daily values of the probability density function of $|\mathrm{d} H / \mathrm{d} t|$ in $2011-2013$ for all stations with data from noon (red), midnight (blue) and full day (black). The panels display the different stations according to quasi-dipole geomagnetic latitude.

The monthly averaged $|\mathrm{d} H / \mathrm{d} t|$ for midnight (Figure 4) resemble the full-MLT values very closely for all stations. Furthermore, the seasonal variation of $|\mathrm{d} H / \mathrm{d} t|$ is very similar to noon and other MLTs. This activity is particularly true for the polar cap and north oval stations. The south oval stations have slightly higher fluctuation levels at the midnight sector than at other local times. The fact that the fluctuation level at midnight is so close to the full-MLT level, despite the increased noon activity in summer at the northernmost stations, suggests that the noon enhancement is rather limited in MLT.

\section{Probability Density of $|\mathrm{d} H / \mathrm{d} t|$ Fluctuations}

We have calculated the PDF of $|\mathrm{d} H / \mathrm{d} t|$ fluctuations for each Greenland station for the entire time span from 2011 to 2013 in daily resolution. Figure 5 shows the separate PDFs for noon and midnight. Full-MLT distributions are also displayed for comparison.

The PDFs of $|\mathrm{d} H / \mathrm{d} t|$ for the polar cap stations SVS and KUV are quite similar. At midnight the mean of the PDFs are about 0.04 to $0.05 \mathrm{nT} / \mathrm{S}$. At noon, the $|\mathrm{d} H / \mathrm{d} t|$ are more spread out, with means at 0.07 and $0.08 \mathrm{nT} / \mathrm{s}$, respectively. The kurtosis, that is, the spikiness, of the distribution, is larger at midnight for both stations, reflecting the more even distribution of values. It is obvious that the noon and midnight PDFs are very different in the polar cap, reflecting the differences seen in Figures 3 and 4. The full-MLT distributions seem to settle between the two distributions but resemble the midnight ones more closely.

The north oval stations DMH and UMQ (and partly GDH) follow similar PDF patterns as the two polar cap stations but with the difference that both noon and midnight PDFs for DMH and UMQ are shifted to slightly larger values than those for SVS and KUV. The DMH (UMQ) noon and midnight means are 0.06 and $0.05 \mathrm{nT} / \mathrm{s}$ $(0.08$ and $0.06 \mathrm{nT} / \mathrm{s})$, respectively. The UPN magnetic data feature a markedly different PDF pattern than other north oval stations, with both time sectors displaying a very wide distribution from 0.06 to $0.14 \mathrm{nT} / \mathrm{s}$. For UPN, $\mathrm{DMH}$, and $\mathrm{UMQ}$, the kurtosis and skewness of the distributions vary less between noon and midnight than with the northernmost stations.

THL shows a very distinct behavior of PDF compared with the other examined stations. There are no daily average values of $|\mathrm{d} H / \mathrm{d} t|$ smaller than $0.10 \mathrm{nT} / \mathrm{s}$ in THL data. This is very probably due to the lower time resolution of the instrument, as noted in section 3 . The distributions are also very similar across the three different MLT sectors. 
UPN generally depicts the highest monthly values of $|\mathrm{d} H / \mathrm{d} t|$ among the north oval stations, even among all stations (see Figures 2-4). Furthermore, UPN shows several peaks that are not observed at any other station. Figure 5 suggests that UPN has considerably higher sensitivity to the small fluctuations of the magnetic field than the other stations of the Greenland network. Therefore, the UPN data form an outlier among the fluctuation levels at the Greenland stations and have to be interpreted with care. Station GDH has a markedly more even distribution of values in both midnight and noon sector, with means at 0.06 and $0.08 \mathrm{nT} / \mathrm{s}$, respectively.

The PDFs of the south oval stations display high values at station STF and drift to lower values at lower-latitude stations. The typical feature in the PDFs of the south oval stations is that the midnight low value peak decreases and the midnight PDF has a long tail of large values. In fact, at all south oval stations, the midnight PDF is above the high noon PDF at the high end of the distribution.

Means of PDF at the south oval stations FHB (SKT) are 0.06 and $0.05 \mathrm{nT} / \mathrm{s}(0.07$ and $0.08 \mathrm{nT} / \mathrm{s})$ for high noon and midnight, respectively. At station NAQ, the PDF's means of $|\mathrm{d} H / \mathrm{d} t|$ are 0.05 and $0.06 \mathrm{nT} / \mathrm{s}$ for noon and midnight. The midnight kurtosis values are far lower for southern stations in the midnight sector than for northern stations, as can be seen in the much wider distribution for the southern stations.

When looking at the PDFs of the 12 stations together, we can see that the midnight and noon MLT distributions change places, with the clear midnight peak at around $0.05 \mathrm{nT} / \mathrm{s}$ changing to a noon peak at $0.05 \mathrm{nT} / \mathrm{s}$ when going from north to south. This can also be seen clearly at other stations and parameters, such as the standard deviation (not shown here).

\section{Fractional Derivative Rates}

The relative occurrence of high-frequency geomagnetic fluctuations at and above a given threshold is examined by a FDR. FDR gives the percentage of time during which $|\mathrm{d} H / \mathrm{d} t|$ meet a certain threshold. FDR does not take into account the amplitude of the magnetic field fluctuations and includes both positive and negative variations. FDR provides a means to characterize the information included in the 1-s resolution data over time periods of several years. Here the threshold level is set to $0.20 \mathrm{nT} / \mathrm{s}$. This threshold quite closely matches the typical rate of decrease of the north-south component of the geomagnetic field during a substorm onset (Tanskanen, 2009) and therefore selects periods associated with significant magnetospheric activity. A major advantage of the FDR is its ability to distinguish between the constant, long-term fluctuating behavior of magnetic field and singular spikes of activity. FDR and $|\mathrm{d} H / \mathrm{d} t|$ are suggested to be used together, to get a more complete picture of the magnetic field fluctuation morphology.

Figure 6 shows the monthly FDR percentages for all stations in 2011-2013 with data from full MLT with $0.20 \mathrm{nT} / \mathrm{s}$ threshold. The temporal evolution of monthly percentages greatly resemble the monthly means of $|\mathrm{d} H / \mathrm{d} t|$ depicted in Figure 2 for all seasons. THL has the largest FDR values of between $20 \%$ and $30 \%$ with systematic summer maxima. However, this is most likely due to the instrument issue as discussed in section 3. The other polar cap stations SVS and KUV record much lower fluctuation levels than THL. However, the seasonal variation at these two stations in Figure 6 is much larger than in Figure 2, the summertime FDR levels being around $10 \%$, but winter levels are only about 3\%. This is in agreement with the different seasonal variations at high noon and midnight (Figures 3 and 4) and with the PDF distribution at high noon and midnight (see Figure 5) at these stations. This displays the power of the FDR parameter to reveal these differences.

The clear seasonal variation with the summer maxima of FDR can be seen in the north oval and south oval stations, especially during 2013. In contrast to Figure 2, the summertime FDRs are somewhat higher in SVS and KUV than at north oval stations, but their winter values are at much lower level than at the north oval stations. The FDR percentages at the south oval stations are, corresponding to Figure 2, somewhat lower than those at north oval stations. As above, the activity at the south oval stations is larger during summer, but the differences between the seasons are smaller for FDR than for $|\mathrm{d} H / \mathrm{d} t|$ in the full-MLT case.

The annual and latitudinal changes of FDR in noon and midnight sectors are studied separately (Figures 7 and 8). The differences between the polar cap stations are more pronounced than in the full-MLT case, with stations SVS and KUV displaying very clear summer maxima. In the north oval, the average fluctuation levels are larger in the noon than in the full-MLT case. Though summer maxima are visible, the pattern is far more varied than the clear increase of polar cap stations. UPN records clear peaks of FDR above $30 \%$, while DMH records very low values of less than $10 \%$. South oval stations measure on average lower FDRs than the polar cap or north oval stations, roughly $9 \%$ for south stations and approximately $15 \%$ and $16 \%$ for north oval and polar cap, 

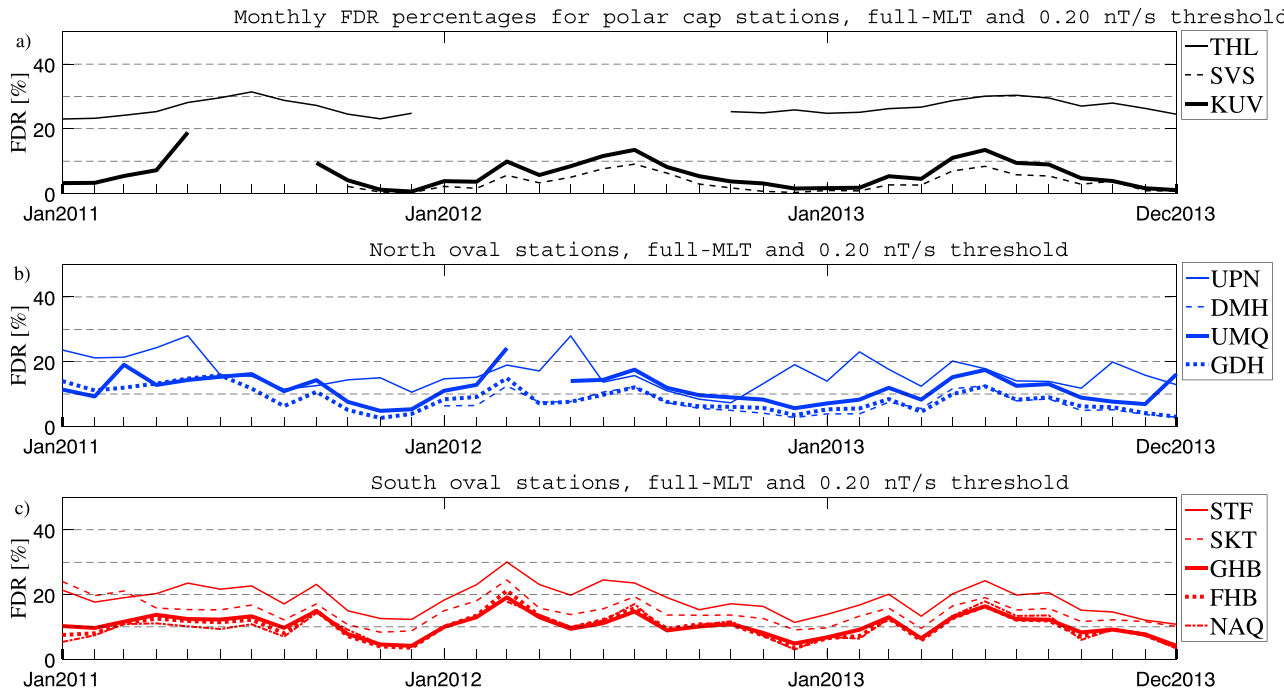

Figure 6. Monthly averaged FDRs in 2011-2013 using all MLT data and $0.20 \mathrm{nT} / \mathrm{s}$ threshold. Stations are grouped similarly as in Figures $2-4 . \mathrm{FDR}=$ fractional derivative rate; $\mathrm{MLT}=$ magnetic local time.

respectively. South oval stations mostly display highly uniform pattern of activity. Magnetic field fluctuation coverage at midnight (Figure 8) show the largest FDR at south oval and smallest at polar cap stations KUV and SVS. In the north oval, the average FDR is approximately $8 \%$, roughly half of that of the noon sector, while in the south oval, the average FDR is approximately $16 \%$, almost twice that of noon. From comparing the different MLT time sectors together, we can see that noon would seem to be more active in the north and midnight in the south.

\section{Latitudinal Variation of $|\mathrm{d} H / \mathrm{d} t|$ and FDR}

The annual means of $|\mathrm{d} H / \mathrm{d} t|$ and FDR are shown for the 12 stations ordered according to their geomagnetic latitude (Figures 9 and 10). The results for the noon, midnight, and the full-MLT range are calculated separately. Both Figures 10 and 11 show quite clear latitudinal trends; for all three years, at seven northernmost stations the levels of $|\mathrm{d} H / \mathrm{d} t|$ and FDR during noon (1000-1400 MLT) are higher than at midnight (2200-0200 MLT), while at the southernmost stations the levels are higher at midnight. The turning point takes place between STF and GDH, at approximately $72^{\circ}$ QDGMlat.
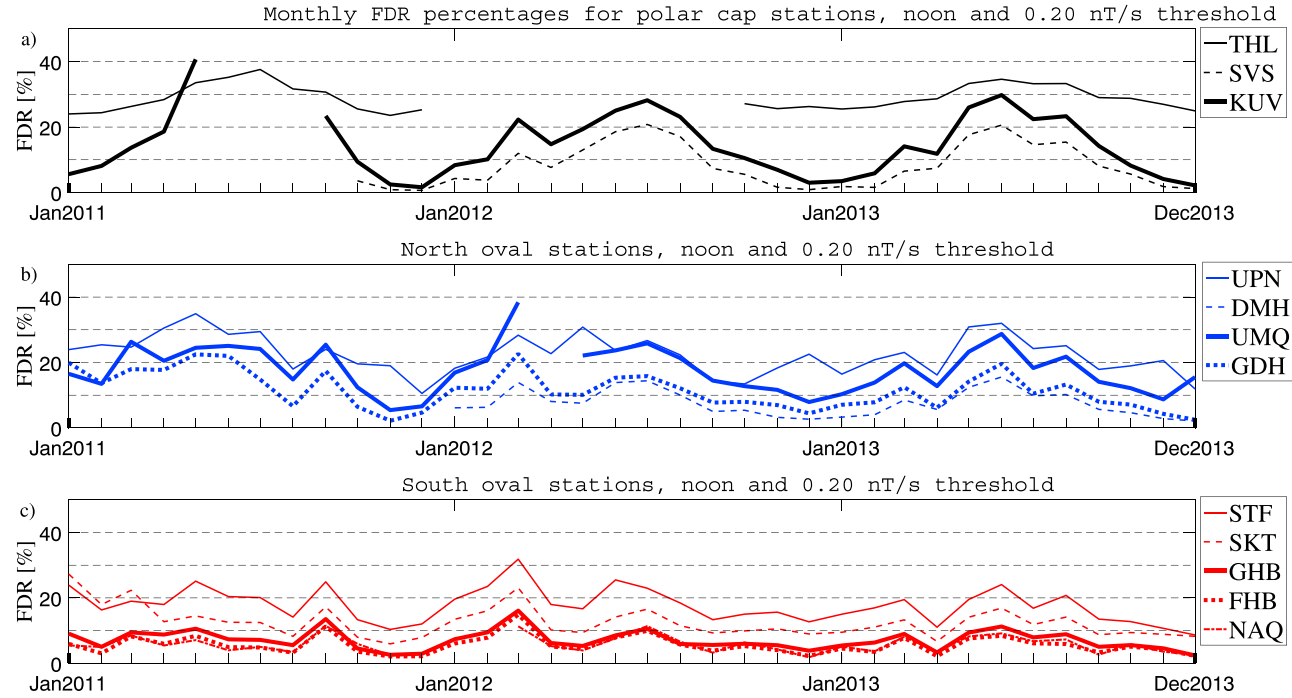

Figure 7. Same as figure 6 , but only data from the noon sector $(10-14 \mathrm{MLT})$ are included. FDR $=$ fractional derivative rate; $\mathrm{MLT}=$ magnetic local time. 

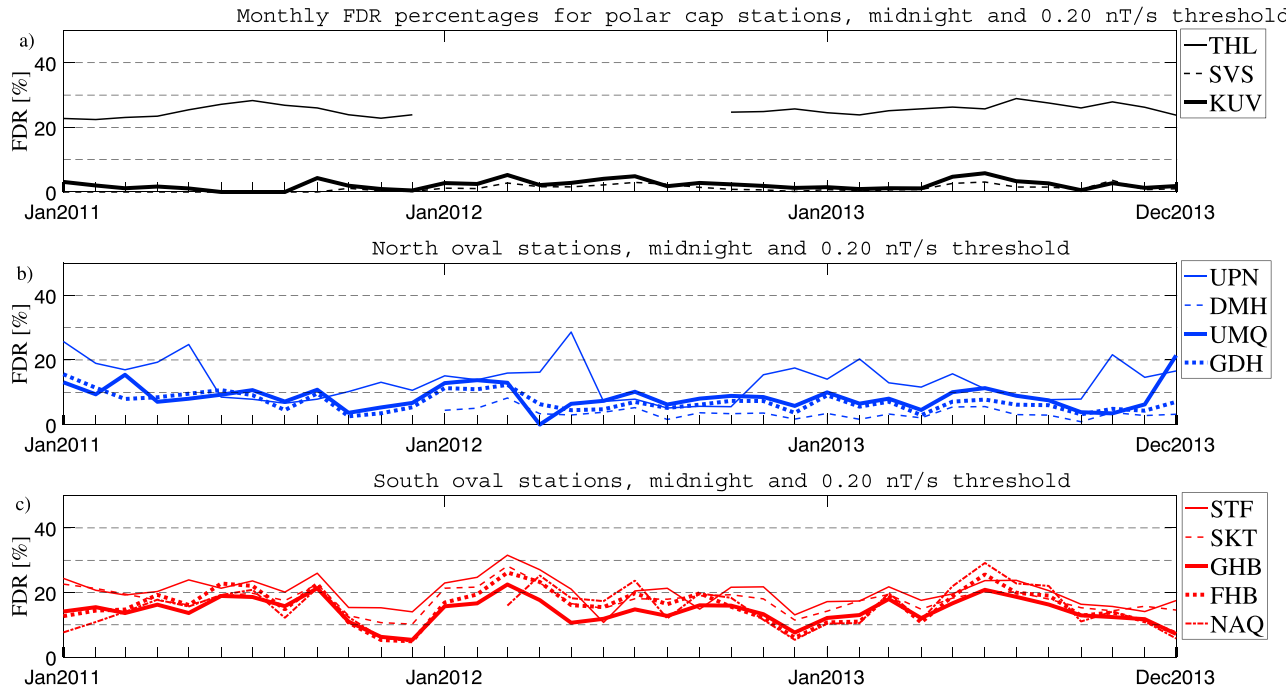

Figure 8. Same as Figure 6, but only data from the midnight sector (22-02 MLT) are included. FDR = fractional derivative rate; $\mathrm{MLT}=$ magnetic local time.

The typical $\mathrm{d} H / \mathrm{d} t$ below $72^{\circ}$ QDGMlat at midnight is $0.12 \mathrm{nT} / \mathrm{s}$ and at high noon around $0.08 \mathrm{nT} / \mathrm{s}$, while above $72^{\circ}$ QDGMlat the typical $\mathrm{d} H / \mathrm{d} t$ is $0.06 \mathrm{nT} / \mathrm{s}$ for midnight and $0.10 \mathrm{nT} / \mathrm{s}$ for noon. This gives $25 \%$ increase of fluctuation rate at noon and 50\% decrease at midnight from below to above $72^{\circ}$ QDGMlat. In THL, the fluctuation rate is almost at the same level for noon and midnight. No large differences are seen in the latitudinal trends of the magnetic field fluctuation rate for years 2011, 2012, and 2013.

The FDR shows the latitudinal variation in the fluctuation rate more clearly than $|\mathrm{d} H / \mathrm{d} t|$. For example, the very low values of FDR are seen at DMH and SVS stations, while $|\mathrm{d} H / \mathrm{d} t|$ stays at much higher level for the same stations. Below $72^{\circ}$ QDGMlat the FDR has around 15\% daily fluctuation coverage at midnight and roughly $7 \%$ coverage at noon. Above $72^{\circ}$ QDGMlat the daily fluctuation coverage is quite variable between the stations thus indicating small-scale structures between the stations.
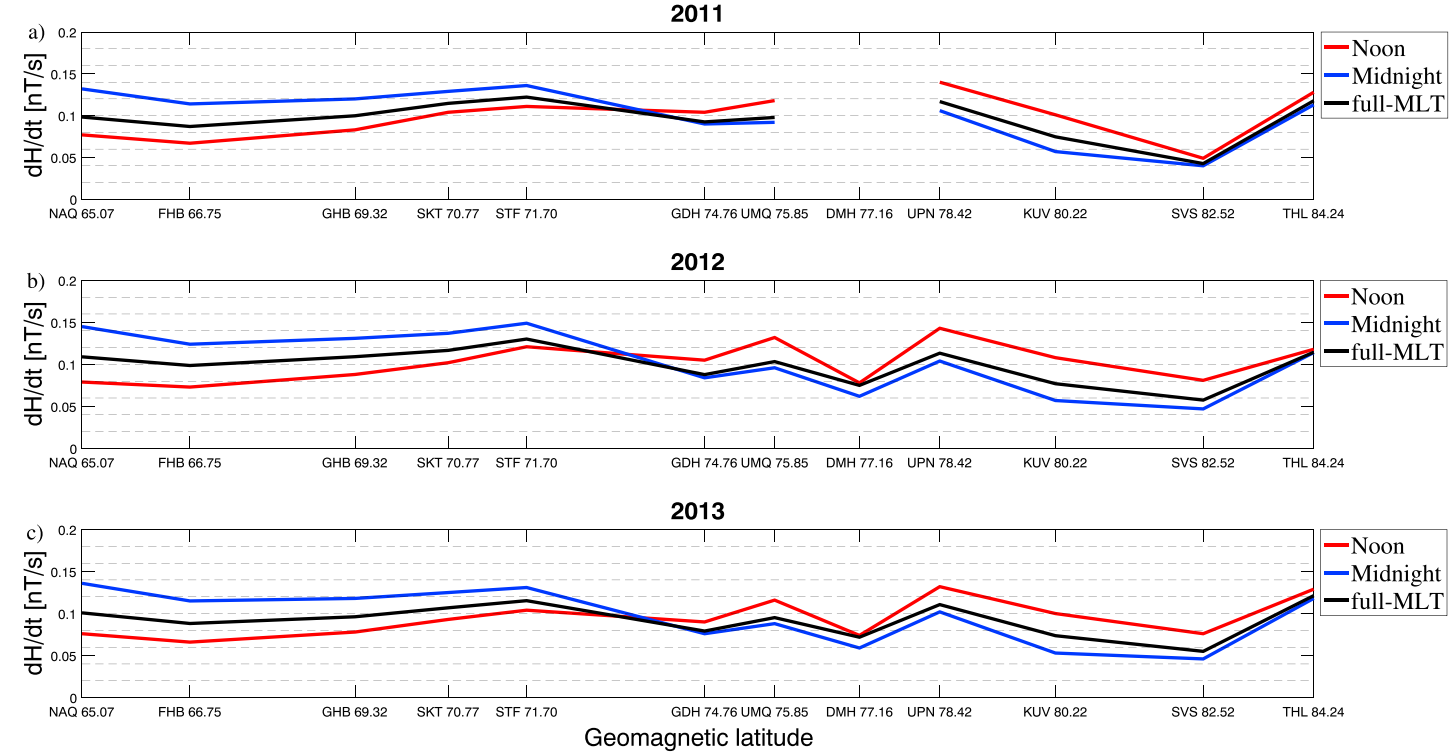

Figure 9. Yearly means of $|\mathrm{d} H / \mathrm{d} t|$ for all stations as a function of quasi-dipole geomagnetic latitude with all MLT sectors. Yearly means for (a) 2011, (b) 2012, and (c) 2013 are depicted. MLT $=$ magnetic local time. 


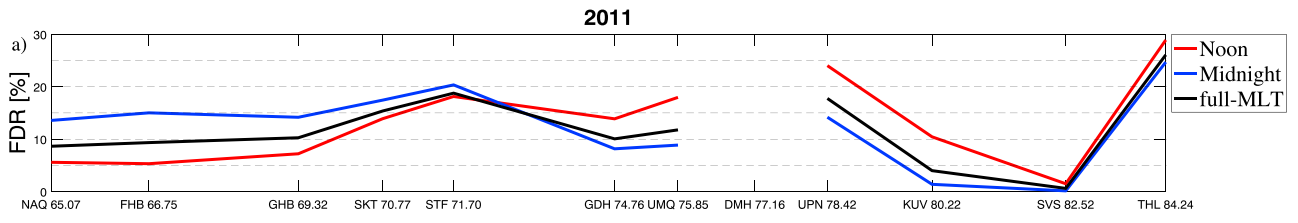

2012

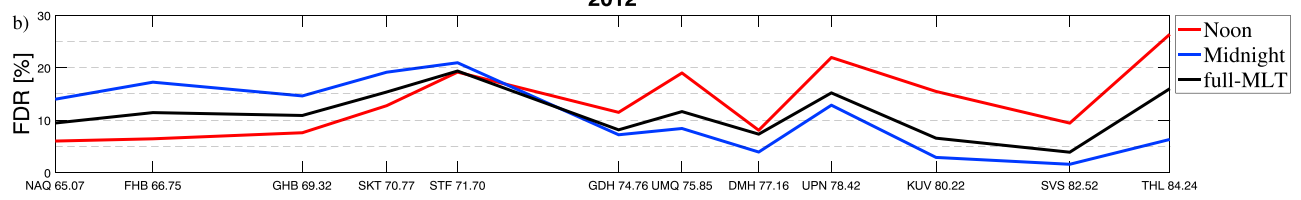

2013

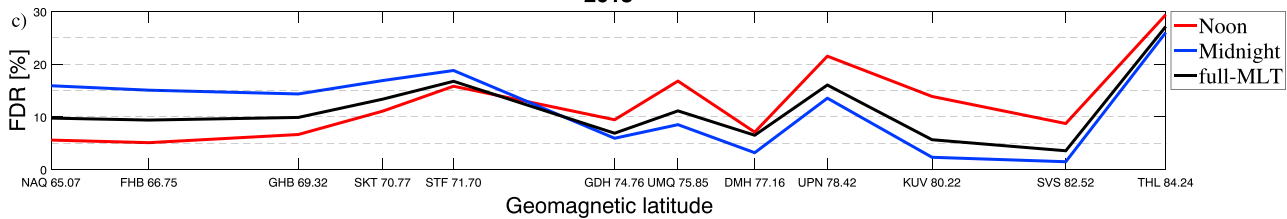

Figure 10. Yearly means of FDR $(0.20 \mathrm{nT} / \mathrm{s}$ threshold) for all stations as a function of quasi-dipole geomagnetic latitude with all MLT sectors. Yearly means for (a) 2011, (b) 2012, and (c) 2013 are depicted. FDR = fractional derivative rate; MLT = magnetic local time.

\section{Interpretation of the Latitudinal Differences}

The northernmost stations THL (83.97 ${ }^{\circ}$ QDGMlat), SVS (82.24 QDGMlat), and KUV (79.91 ${ }^{\circ}$ QDGMlat) record variations within the polar cap, and the high-frequency activity is very probably highly affected by the solar wind most of the time. In SVS and KUV the fluctuation level is clearly lower than at THL due to the lower-latitude location (Figures 2-4). While THL is mainly within the antisunward flow of magnetospheric plasma convection, the two other stations are more close to the epicenter of the antisunward and sunward flow of magnetospheric plasma convection. The distinct behavior of the magnetic field fluctuations observed in the three above mentioned stations is further emphasized by the histograms of $|\mathrm{d} H / \mathrm{d} t|$ distribution (Figure 5). Seasonal variation in polar cap at midnight is almost nonexisting, but at noon a clear summer enhancement is visible.

The north oval stations (UPN, DMH, UMQ, and GDH; $78.11^{\circ}$ to $74.35^{\circ}$ QDGMlat) record similar geomagnetic fluctuations, most likely driven by electrojet currents in response to increased solar wind speed, for example,

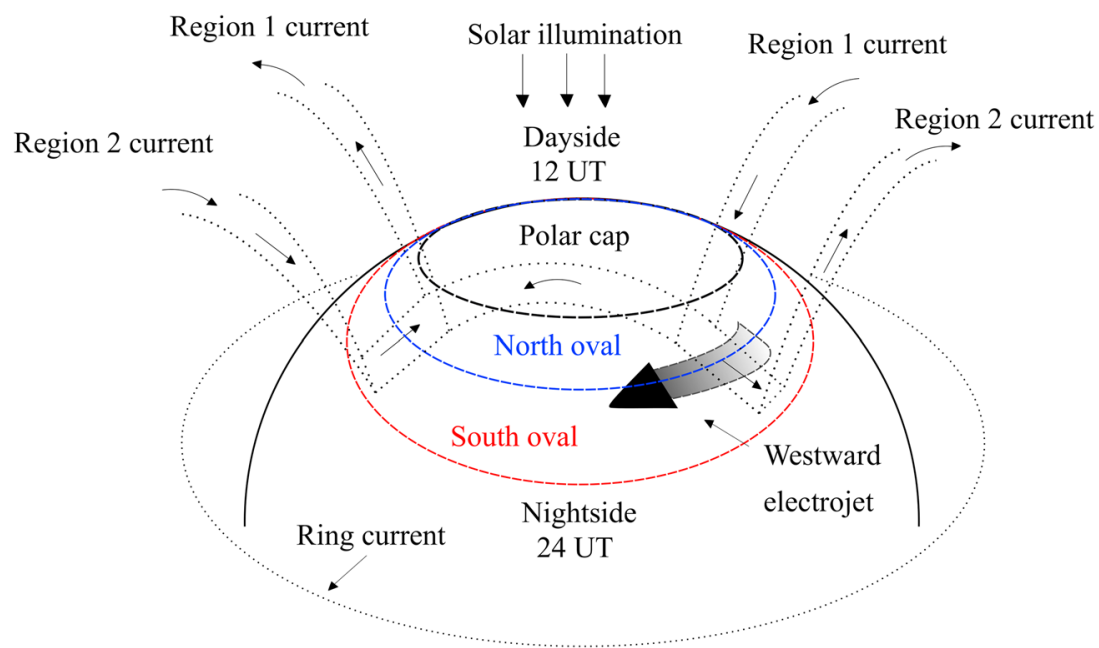

Figure 11. A schematic picture of the three latitudinal sectors, the magnetic fluctuations of which are studied in this paper: polar cap (79-84 QDGMlat), north oval (73-79 QDGMlat), and south oval (64-73 QDGMlat). Dotted lines denote currents, dashed lines denote latitudinal sector boundaries, and the large arrow denotes westward electrojet. The equatorward boundaries of the three latitudinal bins are noted by the colors black, blue, and red for polar cap, north oval, and south oval, respectively. 
FDR percentages for different thresholds at noon in 2013
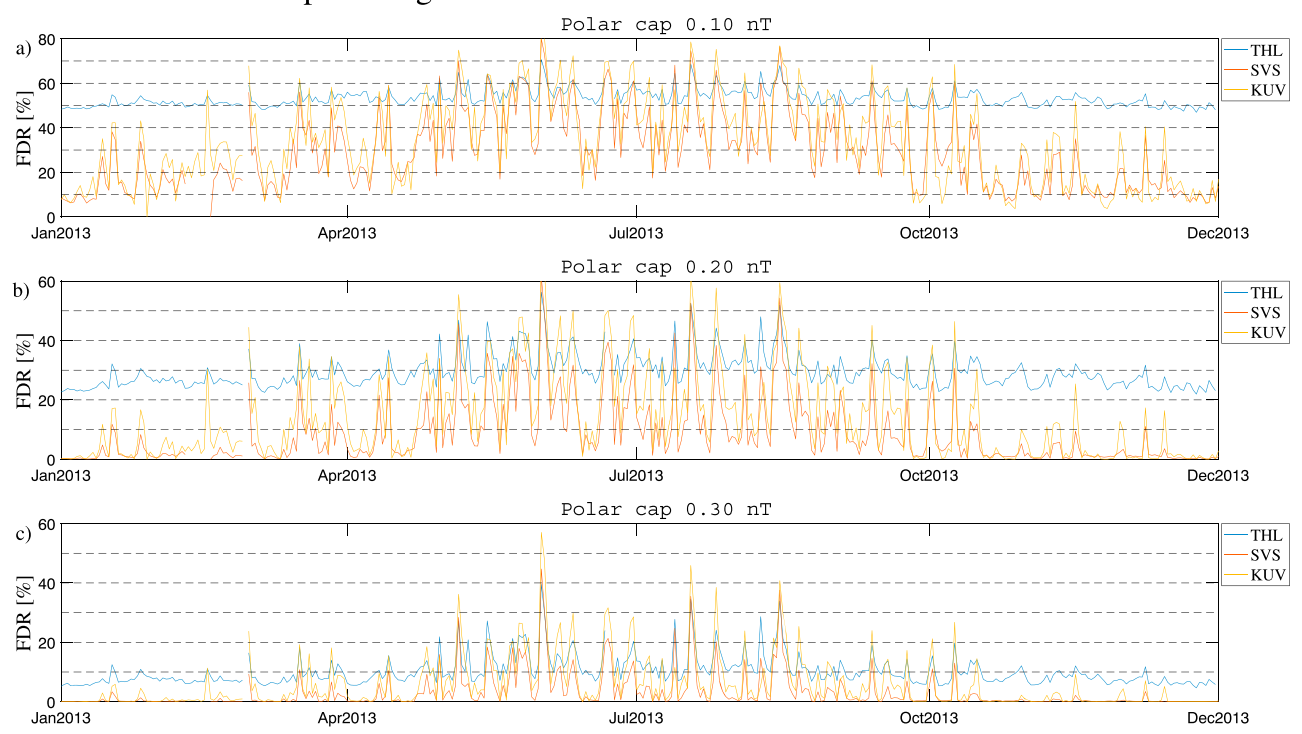

Figure 12. Daily FDR values for polar cap stations in 2013 in the noon (1000-1400) MLT sector. Three different thresholds for $|\mathrm{d} H / \mathrm{d} t|$ are illustrated: (a) 0.10 , (b) 0.20 , and (c) $0.30 \mathrm{nT} / \mathrm{s}$. FDR = fractional derivative rate; MLT = magnetic local time.

HSS, corotating interaction regions, and IMF variations. The north oval stations show clear seasonal variation, unlike polar cap stations, which show almost flat seasonal profile (Figure 4). In the noon sector (Figure 3) the seasonal fluctuation patterns are very similar between the polar cap and north oval latitudes, with summer hosting the largest fluctuations.

The south oval stations are located in latitudes that are typically influenced by geomagnetic storm-related currents, such as the ring current, driven by interplanetary CMEs and shocks. The seasonal and annual trends for all five southernmost stations follow each other, the only exception being station STF, with somewhat higher average $|\mathrm{d} H / \mathrm{d} t|$ (noon $0.11 \mathrm{nT} / \mathrm{s}$, midnight $0.14 \mathrm{nT} / \mathrm{s}$ ) and FDRs (noon $17.7 \%$ and midnight $20.0 \%)$. STF is typically close to the center of the auroral oval and is most likely influenced by auroral electrojets. Overall the south oval stations (STF, SKT, GHB, FHB, and NAQ) exhibit the most uniform behavior of $|\mathrm{d} H / \mathrm{d} t|$.

The most active MLT changes notably according to latitude. With regard to the polar cap stations (THL, SVS, and KUV) the highest $|\mathrm{d} H / \mathrm{d} t|$ increases are seen during noon at summer months. Midnight and full MLT show rather flat levels of $|\mathrm{d} H / \mathrm{d} t|$ in the polar cap (Figures 2 and 4). In the north oval, midnight has markedly higher fluctuation rates compared with the polar cap stations, though there are still high values measured in the noon sector as well. The south oval sector exhibits a notable increase in the midnight fluctuation activity compared with the noon activity. Most likely the northernmost stations noon activity increase is due to increased conductivity in the ionosphere, which is due to solar illumination as well as solar wind.

Figure 11 shows the three different latitudinal sectors studied and related current systems. Regions 1 and 2 currents are high-latitude field-aligned currents with region 1 connecting to the poleward part of the auroral oval and region 2 to the equatorward part. Dayside and nightside are shown separately, as increased conductivity due to solar illumination works mainly in the dayside and magnetotail processes modulate the nightside magnetic fluctuations. Note that the location of the footprints of regions 1 and 2 currents vary over time. At times they are within the north oval, and at other times within the south oval. The variability is not studied here. The driver of geomagnetic fluctuations changes by latitude from illumination-induced changes and solar wind composition to a more nuanced combination of different current systems originated at different parts of the magnetosphere. With regards to MLT variation, the most active sector changes from noon to midnight when going from the polar cap to the south oval latitudes. In the north, this is most likely due to changes of conductance, while the magnetic fluctuations in the south oval are mostly affected by electrojet. The dominant driver and the location of the largest and longest coverage magnetic fluctuations change gradually across the selected stations, depending on the level of geomagnetic activity, season, and solar cycle phase. 


\section{Discussion}

We have studied 1-s sampled magnetic measurements at 12 stations in Greenland during 2011-2013. Magnetic field fluctuations $|\mathrm{d} H / \mathrm{d} t|$ and magnetic field fluctuation coverage parametrized by FDRs were computed for each station separately to examine the level and trends of the high-frequency fluctuations of the geomagnetic field in Greenland. High-frequency geomagnetic fluctuations are observed throughout the entire studied time span and latitudinal range $\left(64.70^{\circ}\right.$ to $83.97^{\circ}$ QDGMlat). We found latitudinal differences in the fluctuation rate in magnetic local time dependence and in annual variability. The latitudinal differences are further highlighted in the annual $|\mathrm{d} H / \mathrm{d} t|$ and FDR plots (Figure 9 and 10) comparing noon, midnight, and full-MLT values for all stations. During all examined years there is a distinct change of pattern between stations STF and $\mathrm{GDH}\left(71^{\circ}\right.$ to $\left.74^{\circ} \mathrm{QDGMlat}\right)$ where the time sector of the highest activity changes from midnight to noon when moving from south to north.

The main results of this paper use the fluctuation threshold of $0.20 \mathrm{nT} / \mathrm{s}$. In addition to the $0.20 \mathrm{nT} / \mathrm{s}$ threshold, we tested two other values: 0.10 and $0.30 \mathrm{nT} / \mathrm{s}$. We found that with the $0.20 \mathrm{nT} / \mathrm{s}$ threshold the latitudinal differences and the unique behavior of the polar cap stations THL, SVS, and KUV, are seen most clearly. Figure 12 shows the daily FDR percentages for these three threshold values in the noon sector for the three polar cap stations in 2013. FDR shows quite high values throughout the year at all stations for a low threshold of $0.10 \mathrm{nT} / \mathrm{s}$, with FDR values decreasing systematically with increasing the threshold.

FDR increases considerably during the summer months, even more clearly than the monthly $|\mathrm{d} H / \mathrm{d} t| \mathrm{val}-$ ues (see Figures 2 to 4). A notable pattern in Figure 12 is that THL maintains an almost constant FDR level throughout the year for all threshold values, increasing less during summer than the other two stations. These continuous magnetic field fluctuations observed in THL clearly show the lower accuracy of the data in THL (as discussed in section 3). THL station indeed has a uniformly flat seasonal distribution of $|\mathrm{d} H / \mathrm{d} t|$ unique among all analyzed stations. Note also that the change of threshold from 0.10 to $0.20 \mathrm{nT} / \mathrm{s}$ significantly lowers the FDR values, typically from above $40-50 \%$ to $15-30 \%$ in summer for the polar stations.

Previous work on geomagnetic data sets of similar latitude range as used here has been conducted by Tanskanen (2009). They studied seasonal variation based on IMAGE magnetometer measurements from 1993 to 2003 for solar cycles 22 and 23 and found that there is a large year-to-year variation in the seasonal variability. In some years, the spring or fall activity dominates, while in others either winter or summer can be the dominant season. This study shows that, for example, in 2012 the spring activity exceeds the geomagnetic activity in other seasons, while in 2013 equally strong enhancements are seen in spring and summer, whereas the fall and winter activity is lower.

Tanskanen et al. (2017) studied the seasonal variation of high-latitude geomagnetic activity in 1995-2014 using the IL index and in 1966-2014 using the $A L$ index. They found that during the past 45 years, only less than one fourth of the individual years follow the classical two-equinox maximum pattern. Their results in the years 2012 to 2013 agree with our findings in that there are summer maxima both in 2012 and 2013, along with spring maxima in 2012 and 2013, respectively.

Tavares et al. (1997) studied semiannual variation in Greenland from 1981 to 1990 (solar cycles 21 and 22) and found a distinct activity increase during summer, matching with the results of this paper. However, as they did not report on the variability of the fluctuation rates in geomagnetic disturbances, their results cannot be compared in detail with our results. Tavares et al. (1997) utilized stations THL, UPN, UMQ, GDH, ATU, STF, $\mathrm{GHB}, \mathrm{FHB}$, and NAQ, that is, the same latitudinal range but less dense latitudinal coverage compared with the Greenland station selection used here.

Myllys et al. (2015) studied the standard deviations of north-south components of the geomagnetic field and showed that the regions 73 to $75^{\circ} \mathrm{CGMlat}$ latitude correlate better with high-speed solar wind and substorm activity, while the regions south of that correlate with CMEs. These results agree with our results that the polar cap is mainly driven by the solar wind. The results of Juusola et al. (2015), that ionospheric equivalent current vectors have two MLT peaks (premidnight sector and prenoon MLT 0800-1000 sector), agree with our results in that the noon sector is the most active MLT in the north oval while the midnight MLT sector is the most active in southern Greenland. The prenoon activity peak seems to correlate with fast solar wind, while the premidnight peak seems to correlate with the IMF southward orientation. 
Our results for the southern latitudes of Greenland west coast chain are in agreement with Viljanen and Tanskanen (2011), who found that $|\mathrm{d} H / \mathrm{d} t|$ values are high around midnight and early morning hours, as well as that large $|\mathrm{d} H / \mathrm{d} t|$ are predominantly observed in association with westward electrojets.

Russell and McPherron (1973) studied seasonal variation in geomagnetic activity over several years. They found enhanced activity in spring and fall when studying multiyear averaged data. Although the two-equinox pattern in geomagnetic variation is seen in the multiyear averages, only one fourth of the year between 1966 and 2014 show this pattern (Tanskanen et al., 2017). In addition to large year-to-year variability, we found distinct latitudinal differences on seasonal variation. Our data set shows enhanced spring and fall most clearly at the south oval stations. Summer enhancements are seen at polar cap stations especially during high noon hours, while the north oval stations are more ambiguous, displaying both spring and fall as well as summer enhancements.

Watermann and Gleisner (2009) used $|\mathrm{d} H / \mathrm{d} t|$ from Greenland and Denmark from 2003 to 2005 to study GICs under storm time conditions and their effects on ground-based infrastructure. They used measurements sampled over 10-s intervals, and they found out that time derivatives are the largest at auroral latitudes during strongly disturbed conditions (Dst index of -100 to $-200 \mathrm{nT}$ ). This can be seen also in our results, with the south oval stations displaying on average the largest $|\mathrm{d} H / \mathrm{d} t|$ values.

Greenland magnetometers have been utilized to study high-latitude electric fields and currents, for example, by Friis-Christensen et al. (1985). They combined Greenland magnetic data with IMF measurements from MES 2 satellite to produce a model on IMF influence on high-latitude electric fields. Their results show that the system of ionospheric and Birkeland currents near the polar cusp exists independently of the system of region 1 and region 2 field-aligned currents. This coincides with our results of distinct, and highly varied, latitudinal behavior across our stations.

The North Polar Cap index PCN (Troshichev et al., 2006) is measured at station THL. The index uses 1-min averaged value; thus, the instrument issues reported in section 3 do not affect the measurements. Stauning et al. (2008) studied the correlation between different solar wind parameters and the Polar Cap indices PCN and PCS (South Polar Cap). They found that the Polar Cap (PC) indices track very well the average solar wind geoeffective electric field strength. The PC indices also closely relates to the Dst index. The PC indices displays only weak dependence on the level of auroral disturbances; this can also be seen in our results, as polar cap stations do not display the strong variations of geomagnetic fluctuations.

The nature of the FDR method to illustrate the coverage, rather than the amplitude, of the geomagnetic fluctuations allows it to provide information in addition to the $|\mathrm{d} H / \mathrm{d} t|$ measurements of the magnetic field. Traditional $|\mathrm{d} H / \mathrm{d} t|$ for the longer time frames tend to be heavily influenced by large single events. Thus, fluctuations in different timescales are not properly differentiated, especially in longer timescales. FDR on the other hand, as being a measure of fluctuation coverage, gives information on the long-term variability of magnetic field fluctuations. Study of FDR and $|\mathrm{d} H / \mathrm{d} t|$ will together allow for a more complete picture of the disturbances in the geomagnetic environment. In this study, both the amplitude and the coverage of fluctuations are presented. Furthermore, magnetic field fluctuations can be very localized, and thus detailed knowledge on the latitudinal distribution of the magnetic field behavior is needed.

Systems where the high time resolution fluctuations play an important role include transformers, power transmission systems, oil and gas pipelines, satellite and airline navigation systems, and wireless telecommunication (A. Pulkkinen et al., 2017). A plausible situation where detailed knowledge of geomagnetic environment would be useful is the construction of a new pipeline. Should it cover a large geographic area, especially latitudinally, the different background fluctuations should be known in detail. Information on the fluctuation coverage in addition to $|\mathrm{d} H / \mathrm{d} t|$ would be valuable to forecast incoming space weather anomalies. The presented method is most valuable in the arctic regions, where the fluctuations are present most of the time, while in middle and low latitudes, the rapid magnetic field fluctuations are more rare. The increased commercial activity in the arctic in recent years makes targeted space weather studies and forecasting more urgent. There is an ongoing debate on how detrimental the constant small-amplitude fluctuations can be to different types of infrastructure. If this is the case, FDR would be needed to better protect the infrastructure for rapid magnetic field fluctuations and their effects. 


\section{Conclusions}

Based on the study of high time resolution (1-s) magnetic field measurements covering latitudinal range in Greenland from $64.70^{\circ}$ to $83.97^{\circ}$ QDGMlat, we arrive at the following conclusions:

1. There is a notable latitudinal dependence on the monthly geomagnetic fluctuation rates of $|\mathrm{d} H / \mathrm{d} t|$ and FDR. The highest monthly averages at seven northernmost stations (THL, SVS, KUV, UPN, DMH, UMQ, and $\mathrm{GDH})$ are measured at noon (1000-1400 MLT), while the largest monthly averages at five southernmost stations (STF, SKT, GHB, FHB, and NAQ) are at midnight (2200-0200 MLT). The dominant MLT sector changes between GDH and STF roughly at $72^{\circ}$ QDGMlat, which is close to the center of the auroral oval.

2. The three polar cap stations (THL, SVS, and KUV) observe average $|\mathrm{d} H / \mathrm{d} t|$ values of roughly $0.08 \mathrm{nT} / \mathrm{s}$. They are influenced by their location in the polar cap and are probably directly driven by solar wind. The north oval stations (UPN, DMH, UMQ, and GDH) measure average $|\mathrm{d} H / \mathrm{d} t|$ values of roughly $0.09 \mathrm{nT} / \mathrm{s}$ and are most likely driven by electrojets. South oval stations (STF, SKT, GHB, FHB, and NAQ) measure average $\mathrm{d} H / \mathrm{d} t$ values of roughly $0.11 \mathrm{nT} / \mathrm{s}$, and they seem to be influenced by the electrojets as well as ring current.

3. Geomagnetic field variations have been analyzed by the newly developed measure, FDR, which is used to show the magnetic field fluctuation coverage instead of fluctuation amplitude $\mathrm{d} H / \mathrm{d} t$. By using the FDR, we were able to find out that large magnetic field fluctuations exceeding $0.2 \mathrm{nT} / \mathrm{s}$ are observed $10-30 \%$ of the time in the Greenland west coast, depending on the solar cycle phase and station locations. The latitudinal variation in the fluctuation coverage was larger than that in the fluctuation amplitude, giving valuable information on the continuous and periodic high-resolution magnetic field fluctuations.

4. In the years $2011-2013$, the polar cap stations show a distinct summer increase, and a corresponding winter decrease, of geomagnetic fluctuation rates during noon, but during midnight hours the level of fluctuations is extremely constant throughout the years. This is most likely due to the changes in conductivity modulated by solar illumination. Meanwhile in the south, the distribution of maxima is far more varied, with spring, autumn, and summer maxima all visible in the data. This can be seen in both the noon and midnight data.

\section{References}

Magnetometer data from the Greenland Magnetometer Array were provided by the National Space Institute at the Technical University of Denmark (DTU Space), and the measurements are available at $\mathrm{ftp}: / / \mathrm{ftp}$. space.dtu.dk/data/Ground magnetometers/Adjusted/. The M_map was used to create the maps for the visualization of the measurements (https://www.eoas.ubc.ca/rich/ map.html). We acknowledge the financial support by the Academy of Finland to the ReSoLVE Centre of Excellence (project 272157), Geoscientific infrastructure G-EPOS (project 293488), and EXWE within SAFIR program. We thank Ari Viljanen and Andrew Dimmock for their valuable ideas and comments on the manuscript and Claudia Stolle, Jürgen Matzka, Anne Willers, and Lars Pedersen for their help with DTU data.
Akasofu, S.-I. (1964). The development of the auroral substorm. Planetary and Space Science, 12(4), 273-282.

Emmert, J. T., Richmond, A. D., \& Drob, D. P. (2010). A computationally compact representation of Magnetic-Apex and Quasi-Dipole coordinates with smooth base vectors. Journal of Geophysical Research, 115, A08322. https://doi.org/10.1029/2010JA015326

Finch, I. D., Lockwood, M. L., \& Rouillard, A. P. (2008). Effects of solar wind magnetosphere coupling recorded at different geomagnetic latitudes: Separation of directly-driven and storage/release systems. Geophysical Research Letters, $35, \mathrm{~L} 21105$. https://doi.org/10.1029/2008GL035399

Friis-Christensen, E., Kamide, Y., Richmond, A. D., \& Matsushita, S. (1985). Interplanetary magnetic field control of high-latitude electric fields and currents determined from Greenland Magnetometer data. Journal of Geophysical Research, 90(A2), 1325-1338.

Gonzalez, W. D., Joselyn, J. A., Kamide, Y., Kroehl, H. W., Rostoker, G., Tsurutani, B. T., \& Vasyliunas, V. M. (1994). What is a geomagnetic storm? Journal of Geophysical Research, 99(A4), 5771-5792.

Guo, J., Feng, X., Pulkkinen, T. I., Tanskanen, E. I., Xu, W., Lei, J., \& Emery, B. A. (2012). Auroral electrojets variations caused by recurrent high-speed solar wind streams during the extreme solar minimum of 2008. Journal of Geophysical Research, 117, A04307. https://doi.org/10.1029/2011JA017458

Holappa, L., Mursula, K., \& Asikainen, T. (2014). A new method to estimate annual solar wind parameters and contributions of different solar wind structures to geomagnetic activity. Journal of Geophysical Research: Space Physics, 119, 9407-9418. https://doi.org/10.1002/2014JA020599

Holappa, L., Mursula, K., Asikainen, T., \& Richardson, I. G. (2014). Annual fractions of high-speed streams from principal component analysis of local geomagnetic activity. Journal of Geophysical Research: Space Physics, 119, 4544-4555. https://doi.org/10.1002/2014JA019958

Juusola, L., Kauristie, K., van de Kamp, M., Tanskanen, E. I., Mursula, K., Asikainen, T., et al. (2015). Solar wind control of ionospheric equivalent currents and their time derivatives. Journal of Geophysical Research: Space Physics, 120, 4971-4992. https://doi.org/10.1002/2015JA021204

Kivelson, M., \& Russell, C. T. (1995). Introduction to space physics. Cambridge, UK: Cambridge University Press.

Koskinen, H. (2011). Physics of space storms: From the solar surface to the Earth. Springer Science \& Business Media.

Koskinen, H., Tanskanen, E., Pirjola, R., Pulkkinen, A., Dyer, C., Rodgers, D., et al. (2001). Rationale for a European space weather programme. Finnish Meteorological Institute.

Lukianova, R., Mursula, K., \& Kozlovsky, A. (2012). Response of the polar magnetic field intensity to the exceptionally high solar wind streams in 2003. Geophysical Research Letters, 39, L04101. https://doi.org/10.1029/2011GL050420

Mann, I. R., Milling, D. K., Rae, I. J., Ozeke, L. G., Kale, A., Kale, Z. C., et al. (2008). The upgraded CARISMA magnetometer array in the THEMIS era. Space Science Reviews, 141(1-4), 413-451.

Mursula, K., Lukianova, R., \& Holappa, L. (2015). Occurrence of high-speed solar wind streams over the grand modern maximum. The Astrophysical Journal, 801(1), 30.

Myllys, M., Partamies, N., \& Juusola, L. (2015). Latitude dependence of long-term geomagnetic activity and its solar wind drivers. Annals of Geophysics, 33(5), 573-581.

Pulkkinen, A., Bernabeu, E., Thomson, A., Viljanen, A., Pirjola, R., Boteler, D., et al. (2017). Geomagnetically induced currents: Science, engineering, and applications readiness. Space Weather, 15, 828-856. https://doi.org/10.1002/2016SW001501

Pulkkinen, T. I., Tanskanen, E. I., Viljanen, A., Partamies, N., \& Kauristie, K. (2011). Auroral electrojets during deep solar minimum at the end of solar cycle 23. Journal of Geophysical Research, 116, A04207. https://doi.org/10.1029/2010JA016098 
Russell, C. T., \& McPherron, R. L. (1973). Semiannual variation of geomagnetic activity. Journal of Geophysical Research, 78(1), $92-108$. Stauning, P., Troshichev, O., \& Janzhura, A. (2008). The polar cap (PC) indices: Relations to solar wind parameters and global magnetic activity. Journal of Atmospheric and Solar-Terrestrial Physics, 70(18), 2246-2261.

Tanskanen, E. I. (2009). A comprehensive high-throughput analysis of substorms observed by IMAGE magnetometer network: Years 1993-2003 examined. Journal of Geophysical Research, 114, A05204. https://doi.org/10.1029/2008JA013682

Tanskanen, E. I., Hynönen, R., \& Mursula, K. (2017). Seasonal variation of high-latitude geomagnetic activity in individual years. Journal of Geophysical Research: Space Physics, 122, 10,058-10,071. https://doi.org/10.1002/2017JA024276

Tanskanen, E., Pulkkinen, T. I., Koskinen, H. E. J., \& Slavin, J. A. (2002). Substorm energy budget during low and high solar activity: 1997 and 1999 compared. Journal of Geophysical Research, 107(A6), 1086. https://doi.org/10.1029/2001JA900153

Tavares, M., Friis-Christensen, E., Moretto, T., \& Vennerstrøm, S. (1997). Semiannual variation of geomagnetic activity in the Greenland magnetometer chain. Physics and Chemistry of the Earth, 22(7), 685-689.

Troshichev, O., Janzhura, A., \& Stauning, P. (2006). Unified PCN and PCS indices: Method of calculation, physical sense, and dependence on the IMF azimuthal and northward components. Journal of Geophysical Research, 111, A05208. https://doi.org/10.1029/2005JA011402

Viljanen, A., \& Tanskanen, E. (2011). Climatology of rapid geomagnetic variations at high latitudes over two solar cycles. Annals of Geophysics, 29(10), 1783-1792.

Watermann, J., \& Gleisner, H. (2009). Geomagnetic variations and their time derivatives during geomagnetic storms at different levels of intensity. Acta Geophysica, 57(1), 197-208. 